\title{
Return Migration and Optimal Tax Rules-a Hysteresis Case
}

\section{Sinikka Hämäläinen}

Published online: 4 July 2009

(C) International Atlantic Economic Society 2009

\section{JEL E62 · F20}

The paper provides some insights into the return behavior of migrant workers. In particular, we investigate the effects of migration on optimal tax rules when individuals have entrenched habits. We model the migration process starting from the choice being made by an individual. Individuals are seen as having entrenched habits which signify various sources of resistance to a change. The presence of habit threshold assumption creates a situation, where the utility change necessary to attract a given number of people back has to be greater than the change that previously caused them to emigrate. Habit formation making people to resist changes lowers the elasticity of return migration. So, the habit-hysteresis factor seems to be a good reason to reduce responsiveness of migration to changes in tax rates. The main consequence of this conclusion is that a habit-hysteresis factor makes a tax policy less effective as a migration policy. To perform a migration policy, governments have to look at some alternative policy tools. 